\title{
Does the gender composition of forest and fishery management groups affect resource governance and conservation outcomes? A systematic map
}

\author{
Craig Leisher ${ }^{1 *} \mathbb{D}$, Gheda Temsah², Francesca Booker ${ }^{3,4}$, Michael Day ${ }^{3,4}$, Leah Samberg ${ }^{5}$, Debra Prosnitz ${ }^{2}$,
} Bina Agarwal ${ }^{6}$, Elizabeth Matthews ${ }^{7}$, Dilys Roe ${ }^{3}$, Diane Russell ${ }^{8}$, Terry Sunderland ${ }^{3}$ and David Wilkie ${ }^{7}$

\begin{abstract}
Background: Women often use natural resources differently than men yet frequently have minimal influence on how local resources are managed. An emerging hypothesis is that empowering more women in local resource decision-making may lead to better resource governance and conservation. Here we focus on the forestry and fisheries sectors to answer the question: What is the evidence that the gender composition of forest and fisheries management groups affects resource governance and conservation outcomes? We present a systematic map detailing the geographic and thematic extent of the evidence base and assessing the quality of the evidence, as per a published a priori protocol.

Methods: We screened 11,000+ English-language records in Scopus, CAB abstracts, AGRIS, AGRICOLA, Google Scholar, and Google. The websites of 24 international conservation and development organisations, references of included articles, and relevant systematic reviews were also searched for possible documents. A number of groups and individuals were invited to submit documents through email 'call outs'. The inclusion criteria were that an article refers to women or gender, forests or fisheries, and a resource management group comparison in a non-OECD country plus Mexico and Chile.

Results: Seventeen studies met the inclusion criteria. Four were qualitative and 13 were quantitative. Forest studies outnumbered fisheries studies 14-3. The majority of the studies came from India and Nepal and focused on forest management. All 17 studies identified improvements in local natural resource governance, and three identified conservation improvements when women participated in the management of the resources. Only two studies, however, were rated as high quality based on study design.

Conclusions: For India and Nepal, there is strong and clear evidence of the importance of including women in forest management groups for better resource governance and conservation outcomes. Outside of India and Nepal, there are substantial gaps in the evidence base, but the South Asian evidence presents a compelling case for extending the research to other geographies to see if similar outcomes exist elsewhere and supports a theory of change linking the participation of women in forestry and fisheries management groups with better resource governance and conservation outcomes.
\end{abstract}

Keywords: Community based, Conservation, Equity, Gender mainstreaming, Livelihoods, Sustainability, Systematic review

\footnotetext{
*Correspondence: craig.leisher@tnc.org

${ }^{1}$ The Nature Conservancy (TNC), 4245 N. Fairfax Drive, Arlington,

VA 22203, USA

Full list of author information is available at the end of the article
} 


\section{Background}

The long-term governmental and donor focus on community-based natural resource management has increased the extent to which rural communities in developing countries are empowered to manage their natural resources [1, 2]. Yet community-based natural resource management is not without its challenges. Issues include inequitable access to and control over resources, conflict within communities, unsustainable resource use, and weak participation of significant stakeholders such as the poor and women [3, 4]. Moreover, a number of factors are known to impact the success of community-based natural resource management including the strength of social capital [5], scarcity of resources [6], institutions [7], and in some studies, the gender composition of the resource management group [8].

Forestry and fisheries are two sectors for which developing country governments have increasingly devolved management rights and responsibilities to local communities $[4,9]$. Yet in rural communities, men and women often use forests and fisheries resources differently. In forests, for example, men may focus on timber and profitable non-timber forest products, while women are more likely to focus on firewood and fodder for animals [10]. In fisheries, men may focus on off-shore and highvalue fisheries, while women are more likely to focus on intertidal invertebrates and fish processing [11]. Women often depend on the sustainability of local resources just as men do, yet they frequently have minimal voice in the governance of the resources $[12,13]$.

There could be both ethical and instrumental reasons for giving a greater voice to women in local resource governance. Ethically, improving equity in resource allocation as well as in decision-making could better balance the needs of both men and women [14]. Instrumentally, it could help make resource use more sustainable as well as improve decision-making in natural resource management. In the business sector there is evidence that decision-making groups that include both men and women have better outcomes than male-only or female-only groups. A 2012 study, for example, of 2360 of the largest companies globally found that, over a 6-year period, companies with women represented on their Boards of Directors had better financial performance than companies with men-only boards [15]. In another large study, students from 2200 business schools in 128 countries competed in teams of three in a business strategy game. When the data for 3 years of the game were analysed (37,914 participants), mixed-gender teams consistently outperformed both male and female single-gender teams [16]. In the business world, mixed-gender decision-making has been shown, at least in some instances, to result in better outcomes.

\section{Objective of the map}

Within the conservation and development communities, there is increasing awareness of the role gender plays in natural resource management. Several papers and a book covering gender and forest management in India and Nepal helped catalyse our interest in the topic $[8,17$, 18 . Yet the extent and rigor of the evidence in the nonacademic and academic literature was unknown, and thus a systematic assessment of the evidence was needed. This research was developed in an iterative process during a series of meetings among several of the authors. A consensus was reached to undertake a 'systematic map' of the available evidence. Systematic maps generally involve reviewing a large body of literature to define tractable systematic review questions [19], but here we chose a systematic map because the knowledge base was expected to be insufficient for a full systematic review and meta-analysis, and a systematic map could provide the foundation for further research by identifying what is already known. Here we focus our systematic map on the geographic and thematic extent of the evidence, the quality of the evidence, and the research needs.

Hence the objective of this systematic map is to provide an overview of the existing evidence linking the gender composition of community groups managing natural resources to resource governance and conservation outcomes in forestry and fisheries, and to identify potential areas for future research. The forest and fisheries focus reflects both the expected bulk of the available evidence and the interests and expertise of the organisational partners behind the systematic map.

Our primary question is: What is the evidence that the gender composition of forest and fisheries management groups affects resource governance and conservation outcomes?

This question has the following components:

Population/subject: Forest or fisheries-based communities in non-member countries of the Organization for Economic Cooperation and Development (OECD)

Intervention: Differing gender compositions of natural resource management groups

Comparator: Natural resource management groups with and without women compared quantitatively or qualitatively

Outcomes: $\quad$ All outcomes related to changes in governance, including rule making and compliance, conflict 
resolution, and accountability and transparency. Also, all outcomes related to conservation efficacy, including improvements in forest cover, greater forest protection, and fish species abundance and diversity.

Herein, we define 'gender' as a set of social constructs ascribing to women and men different abilities, attitudes, personality traits, and behavioural patterns as well as the power and systems of differentiation that are revealed in the unequal division of labour and resources between women and men [20]. We also recognize the fact that gender is not two 'immutable categories' but a spectrum [21, 22]. An article was deemed to include gender if it mentions gender-specific treatments, activities, or strategies.

'Forests' are defined as more than 0.5 hectares of land with trees more than $5 \mathrm{~m}$ in height and a canopy cover of more than $10 \%$, or trees able to reach these thresholds in situ [23]. A 'fishery' is the harvest of fish and/or aquatic invertebrates and includes both marine and freshwater. An article was deemed to include forestry or fisheries if it focused on either.

A 'management group' is defined for the purposes of this systematic map as a group of people organized to govern a forest or fishery resource. We distinguish 'management' from 'governance' in that management is what is undertaken in pursuit of specific objectives, while governance is the process of deciding what the objectives should be and how to pursue them [24]. Management and governance typically overlap.

'Governance' is defined as a process by which authority to regulate actions is conferred and the manner in which rules are made. Good governance is associated with: accountability; transparency; protection of rights; equity in application of regulations; social inclusion; and citizen participation $[25,26]$.

'Conservation' is defined as the preservation, protection, or restoration of biodiversity or natural resources.
We chose to focus on non-OECD countries because this is the main target of international development assistance.

\section{Methods}

The methods follow an a priori systematic map protocol. We made two changes from the published protocol [27]: we elected to include qualitative as well as quantitative studies to widen the evidence base; and we added Mexico and Chile as eligible countries, despite their OECD membership, because they still receive international development assistance and have community management of forests and/or fisheries resources. This also widens the potential developing-country evidence base (though in practice it made little difference).

\section{Searches}

The search terms were tested in CABI's CAB abstracts database [28] using the OvidSP platform [29] and Elsevier's Scopus [30]. The project team compiled an initial list of search terms broadly related to the research question's population (using synonyms of 'resource management') and intervention (using synonyms of 'gender'). This list was developed iteratively and further terms were added as they were identified during the literature searches. For searches in $C A B$ abstracts, the $C A B$ thesaurus was used to refine and add search terms [31]. The final iterations of the search strings are given in Table 1.

The following bibliographic databases were searched for publications:

- Scopus

- CAB abstracts

- AGRIS

- AGRICOLA

These databases were selected because Scopus is the largest abstract and citation database for peer-reviewed literature. $C A B$ Abstract indexes publications from 150 countries and is among the more comprehensive title and abstract databases for applied life sciences and the

Table 1 Search strings

\begin{tabular}{|c|c|c|}
\hline & Search string & Number of search results \\
\hline Scopus & $\begin{array}{l}\text { (Women* OR* gender* OR empower*) AND TITLE-ABS-KEY (fisher* OR forest* OR (resource manage- } \\
\text { ment) OR (natural resources) or biodiversity or conservation OR marine) }\end{array}$ & 5279 \\
\hline CAB abstracts & $\begin{array}{l}\text { Forest OR fisheries OR forest management OR fishery management OR community forestry OR } \\
\text { resource management OR forestry resources OR fishery resources AND women OR gender relations } \\
\text { OR social participation OR community involvement OR citizen participation OR participative man- } \\
\text { agement OR employee participation OR participation OR decision making OR empowerment OR } \\
\text { community action OR'decision making' }\end{array}$ & 5359 (after removing duplicates) \\
\hline
\end{tabular}

* is the Boolean search modifier for a root word, stem, or truncation search 
environment. AGRIS [32] and AGRICOLA [33] are smaller bibliographic databases that often have unique holdings relevant to the environment. AGRIS and AGRICOLA use basic search strings and hence were not included in the search string development. Several social science databases were considered but ultimately excluded including Education Resources Information Center (ERIC), the social science research network (SSRN), and EBSCO's social science abstracts. Social science focused databases are excellent for targeted research on a specific topic, but Scopus' 22,000 titles and CAB abstracts 8.1 million records cover much of the same literature as the social science databases and facilitate rapid searches.

Within each database, the results were modified by Boolean operators, wildcards, and limited to relevant subject areas. Searches were undertaken in English and were not restricted by publication date except for $C A B$ abstracts, which begins with 1973 data. Descriptions of the final searches conducted are included in 'Additional file 1: evolution of search strings'.
Google Scholar [34] was searched using simple search terms such as 'gender AND resource management'. Where the search produced more than 200 hits, the first 75 were screened. Otherwise all hits were screened. Searches were also conducted in Google [35] using the same search terms and approach.

We searched 24 websites for publications on gender and natural resources (Table 2). The websites were selected based on a 2012 review by The Nature Conservancy (TNC) of international organisations with a known interest in gender and the advice of gender experts.

We invited the gender experts at the International Union for the Conservation of Nature (IUCN), Conservation International $(\mathrm{CI})$, and World Wildlife Fund (WWF-US), the $1000+$ members of the Poverty and Conservation Learning Group (an international network convened by the International Institute for Environment and Development) [36], and the $40+$ members of the Gender and Environment Working Group [37] to submit relevant documents and articles, and added those that met the inclusion criteria but were not already in

Table 2 List of websites searched for non-academic sources

\begin{tabular}{|c|c|}
\hline Organisation & Website \\
\hline African Development Bank (AfDB) & http://www.afdb.org/en/ \\
\hline Asian Development Bank (ADB) & http://www.adb.org \\
\hline Asian Fisheries Society & http://genderaquafish.org/ \\
\hline Australian Agency for International Development (AusAID) & http://aid.dfat.gov.au/Pages/home.aspx \\
\hline CARE International & http://www.care-international.org/ \\
\hline CARE US & http://www.care.org \\
\hline Center for International Forestry Research (CIFOR) & http://www.cifor.org \\
\hline Convention on Biological Diversity (CBD) & http://www.cbd.int \\
\hline Darwin Initiative & http://www.gov.uk/government/groups/the-darwin-initiative \\
\hline Department for International Development (DFID) & $\begin{array}{l}\text { http://www.gov.uk/government/organisations/department-for-interna- } \\
\text { tional-development }\end{array}$ \\
\hline Food and Agriculture Organisation (FAO) & http://www.fao.org \\
\hline Inter-American Development Bank (IADB) & http://www.iadb.org \\
\hline International Food Policy Research Institute (IFPRI) & http://www.ifpri.org \\
\hline International Fund for Agricultural Development (IFAD) & http://www.ifad.org \\
\hline International Initiative for Impact Evaluation (3ie) & http://www.3ieimpact.org \\
\hline International Institute for Environment and Development (IIED) & http://www.iied.org \\
\hline International Union for Conservation of Nature (IUCN) & http://www.iucn.org \\
\hline Secretariat of the Pacific Community (SPC) & http://www.spc.int \\
\hline United Nations Environment Programme (UNEP) & http://www.unep.org \\
\hline United Nations Development Programme (UNDP) & http://www.undp.org \\
\hline United States Agency for International Development (USAID) & http://www.usaid.gov \\
\hline $\begin{array}{l}\text { Women Organizing for Change in Agriculture and Natural Resource } \\
\text { Management (WOCAN) }\end{array}$ & http://www.wocan.org \\
\hline World Bank & http://www.worldbank.org \\
\hline WorldFish & http://www.worldfishcenter.org \\
\hline
\end{tabular}


the search results. We also 'snowballed' the references of included articles to identify additional relevant articles. Finally, we screened the bibliographies of relevant systematic reviews published by Environmental Evidence [38], 3ie [39], and the Campbell Collaboration [40]. There were no restrictions based on publication status.

\section{Study inclusion criteria}

After the articles identified by the searches were compiled and duplicates removed, the inclusion criteria below were used to identify relevant articles:

$\begin{array}{ll}\text { Relevant population(s): } & \begin{array}{l}\text { Referred to a forest or fish- } \\ \text { eries-based community in } \\ \text { a non-OECD country (plus } \\ \text { Mexico and Chile) }\end{array} \\ \text { Relevant intervention(s): } \begin{array}{l}\text { Referred to women or gender } \\ \text { in the context of a manage- } \\ \text { ment group } \\ \text { Referred to a comparison of } \\ \text { management groups }\end{array} \\ \text { Relevant outcome(s): } \quad \begin{array}{l}\text { Referred to a resource govern- } \\ \text { ance or conservation outcome } \\ \text { All study designs were } \\ \text { included }\end{array}\end{array}$

A Kappa analysis was performed on a random sample of 100 titles and abstracts to measure inter-rater agreement in applying the inclusion criteria. Because there were three reviewers, Fleiss' test [41] was used. After three rounds of Kappa analysis, the inter-rater agreement was above 0.6 at both the title and abstract levels.

The reviewers used a three-stage sequential screening process. We used the screening tool 'Abstrackr' to screen the title and then the abstract [42]. We did not use Abstrackr's semi-automated screening function, though it shows promise for substantially reducing the time needed to screen titles and abstracts [43]. At the title and abstract levels, documents were assessed independently, with each reviewer assigned a portion of the literature. Where there was doubt about whether or not an article met the inclusion criteria, it was retained for assessment at the next stage. After the abstract screening, the full texts of included articles were located, added to an Endnote library, [44] and screened using the inclusion criteria. Full-text electronic or paper copies of the articles and books were obtained.

\section{Potential effect modifiers}

In the full-text articles and book chapters, we noted if there was mention of potential 'effect modifiers' beyond gender, such as landlessness in the community or within the management group, age of participants, age of resource management group, original state of the resource before community protection began, cultural factors, ethnicity/race, caste, wealth, class, occupation, education level of household head, high levels of political and economic inequality in a community, and 'other'. These were included in the study coding, as described below.

\section{Critical appraisal}

We used the Maryland scientific methods scale to categorize quantitative social science studies likely to have high or low internal validity based on the study design [45]. For each quantitative study and the quantitative portion of mixed-method studies, the design was rated from one to five as per the Maryland scientific methods scale, and if the rating was four or above, it was given a 'high' rating for study design. Qualitative studies were rated using the critical appraisal skills programme (CASP) qualitative research checklist [46] which uses ten screening questions to assess quality. Studies that used mixed methods were classified as either predominantly quantitative or primarily qualitative for rating purposes.

\section{Study coding strategy}

The study coding template was designed so that, wherever possible, fixed answers were selected from coded dropdown lists. From each full-text article included, the variables in Table 3 was extracted.

All data were double extracted by two researchers working independently and then reconciled [47] using Microsoft Excel [48].

\section{Results}

\section{Descriptive results}

After duplicates were removed, we screened 11,069 records by title and abstract. Common terms in the search string such as 'gender' and 'resource management' led to a high percentage of irrelevant results such as animal and plant studies. Hence, 10,936 records were excluded at the title or abstract level. Across all sources, we identified 133 studies for full-text review (Fig. 1). We were unable to locate three of the included studies. None of the three is likely to be relevant given that one is an introduction to a book, one is a conference report from a fisheries society meeting, and the other is a newsletter. Ultimately, 17 studies met the inclusion criteria. Of these, nine are peer-reviewed journal articles, four are book chapters, three are conference papers, and one is a thesis. All articles were less than 10 years old, and ten were from the last 10 years. 'Additional file 2: full-text review results' provides the references for the 17 included studies and the 116 excluded studies along with the reasons for exclusion. 
Table 3 Coding variables

\begin{tabular}{|c|c|}
\hline Variable & Details/examples \\
\hline ID & Unique ID for each article \\
\hline \multicolumn{2}{|l|}{ Reviewer } \\
\hline \multicolumn{2}{|l|}{ First author } \\
\hline \multicolumn{2}{|l|}{ Year } \\
\hline \multicolumn{2}{|l|}{ Full reference } \\
\hline \multicolumn{2}{|l|}{ URL } \\
\hline Publication type & $\begin{array}{l}\text { E.g., journal, book chapter, confer- } \\
\text { ence paper, thesis, organisation } \\
\text { report }\end{array}$ \\
\hline Article access issues & $\begin{array}{l}\text { E.g., none, subscription only, author } \\
\text { only }\end{array}$ \\
\hline Biome & Forest, marine or freshwater \\
\hline \multicolumn{2}{|l|}{ Study country/ies } \\
\hline \multicolumn{2}{|l|}{ Study region(s) } \\
\hline Study length & Time over which study undertaken \\
\hline Study description & Short description of study \\
\hline \multicolumn{2}{|l|}{ Project name } \\
\hline Intervention type (primary) & $\begin{array}{l}\text { List of different forest and fish con- } \\
\text { servation and resource manage- } \\
\text { ment interventions }\end{array}$ \\
\hline $\begin{array}{l}\text { Primary outcome (governance, } \\
\text { conservation) }\end{array}$ & $\begin{array}{l}\text { Short description of the primary } \\
\text { outcome }\end{array}$ \\
\hline $\begin{array}{l}\text { Quantitative study design rating } \\
\text { and type }\end{array}$ & $\begin{array}{l}\text { Rating and type of study design on } \\
\text { the five-point scale of the Mary- } \\
\text { land scientific methods scale }\end{array}$ \\
\hline Qualitative study quality rating & $\begin{array}{c}\text { Rating from } 1 \text { to } 10 \text { based on CASP } \\
\text { qualitative research checklist }\end{array}$ \\
\hline Method(s) of data collection & List of data collection method(s) \\
\hline Sample size & Number in sample \\
\hline Sample unit & E.g., individuals, households, groups \\
\hline Comparator type & $\begin{array}{l}\text { E.g., randomised before-after, } \\
\text { control-impact (BACI), non-ran- } \\
\text { domised BACl, temporal, spatial, } \\
\text { other }\end{array}$ \\
\hline Other outcome influences & $\begin{array}{l}\text { Other potential outcome influences } \\
\text { mentioned in the study }\end{array}$ \\
\hline Quantitative study quality rating & $\begin{array}{l}\text { Low, high or not rated (based on } \\
\text { study design rating) }\end{array}$ \\
\hline Qualitative study quality rating & Low, medium and high \\
\hline Additional details & Comments \\
\hline
\end{tabular}

Of the included studies, four were primarily qualitative [49-52] and 13 were primarily quantitative $[8,17,18,53-$ 62]. Of the quantitative studies, the unit of analysis for all but three was the group, and the average sample size was 132 groups. Two studies used households as the unit of analysis [57, 58], and one used fish ponds ('beels') [59].

Geographically, the included studies are concentrated in South Asia. Twelve of the 17 studies are from India and/or Nepal. Latin America, East Africa, and southeast Asia had five studies in total.
We identified 14 forest articles and three fisheries articles (Fig. 2). Within fisheries, two studies addressed freshwater fisheries and one dealt with marine fisheries. 'Additional file 3: study coding results' gives the geographic and categorical data on each included study.

All 17 included studies identified improvements in local natural resource governance when women participated in the management of the resources, and three studies identified resource conservation benefits. Stricter rules (while still allowing for sustainable extraction), greater compliance with rules, greater transparency and accountability, and better conflict resolution were among the reasons for improvements. Additional file 4 summarizes the key findings from each included study.

\section{Differences in the included studies}

The most obvious differences among the studies lie in their design. Among the quantitative studies, seven use regression models with governance indicators as dependent variables and gender composition of groups as the explanatory variable $[17,18,53-56,59]$. Among the remaining quantitative studies, the designs comprise before-after, control-impact quasi-experimental designs from a single site $[57,58]$, a before-after, control-impact quasi-experimental design across multiple sites [8], a before-after comparison [61], a control-impact comparison [60], and a frequency distributions of response for women's, men's, and mixed-gender groups with a least significant difference test for group averages [62]. For the qualitative studies, two use, inter alia, key informant interviews, focus-group discussions, and participant observations [51,52], and one uses key informant interviews, focus group discussions, and secondary information [49]. The fourth uses in-depth interviews and discussions with men and women separately' [50].

Using the Maryland scientific methods scale to assess internal validity based on study design, 11 of the included quantitative studies were rated as having low internal validity given their study designs. One was rated as high because it measures before and after variables in multiple impact and control sites [8], and two studies had designs not covered by the Maryland scientific methods scale: one compared women-headed versus men-headed joint forest management committees [60] and a second compared, inter alia, frequency distributions of response for women's, men's, and mixed-gender groups [62]. For the four qualitative studies assessed with the CASP qualitative research checklist, one was high quality ( 8 out of 10 possible points) [52], one was medium (5 out of 10 possible points) [51], and two were low quality ( $<5$ possible points) $[49,50]$. 


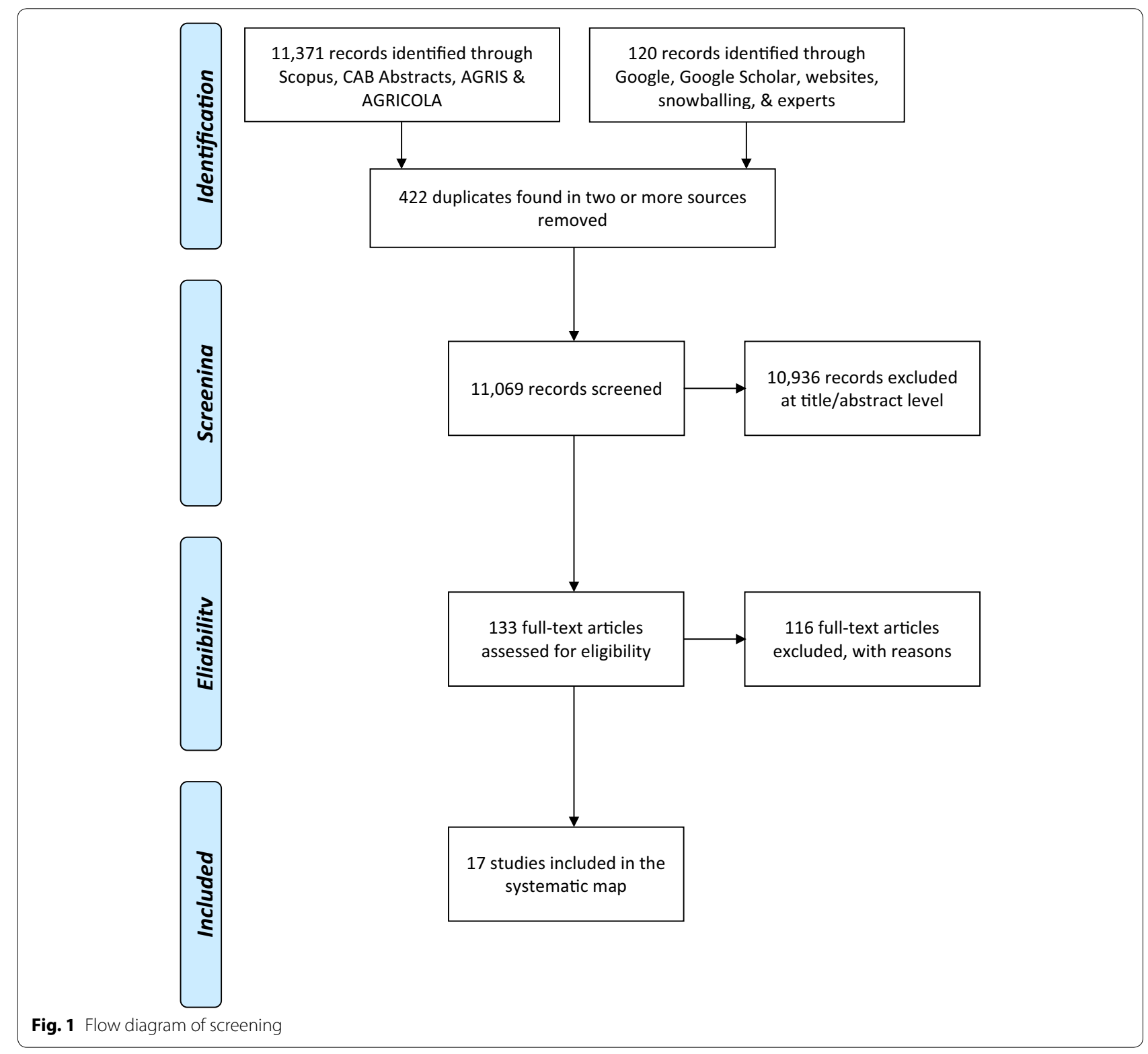

Factors other than the gender compositions of resource management groups can also influence observed outcomes, and another difference among the included studies is which additional negative or positive influences on the outcomes are highlighted. The most frequently mentioned influencer is landlessness. Eight studies note that landlessness may make people more dependent on resources and less compliant with resource regulations $[8,17,18,50,53,54,57,58]$, and one study notes that including landless women in the governance structure increased regulatory compliance suggesting that governance inclusivity of the landless has benefits [17]. Given that the majority of the included studies were in
India and Nepal, not surprisingly caste is a commonly mentioned influencer. For example, having Brahmins, the highest caste, present in a management group may benefit forest protection because they tend to wield traditional authority [8]. Yet a management group in a multi-caste community that is dominated by a high caste can also result in elite capture of the benefits [50]. Four studies highlight wealth among group members as an influencer that often improves resource governance and conservation outcomes $[49,50,56,57]$. Two studies find differing influences from wealth $[17,18]$. Education level of the household head is mentioned by two studies as both a negative and positive outcome influencer $[56,60]$, 


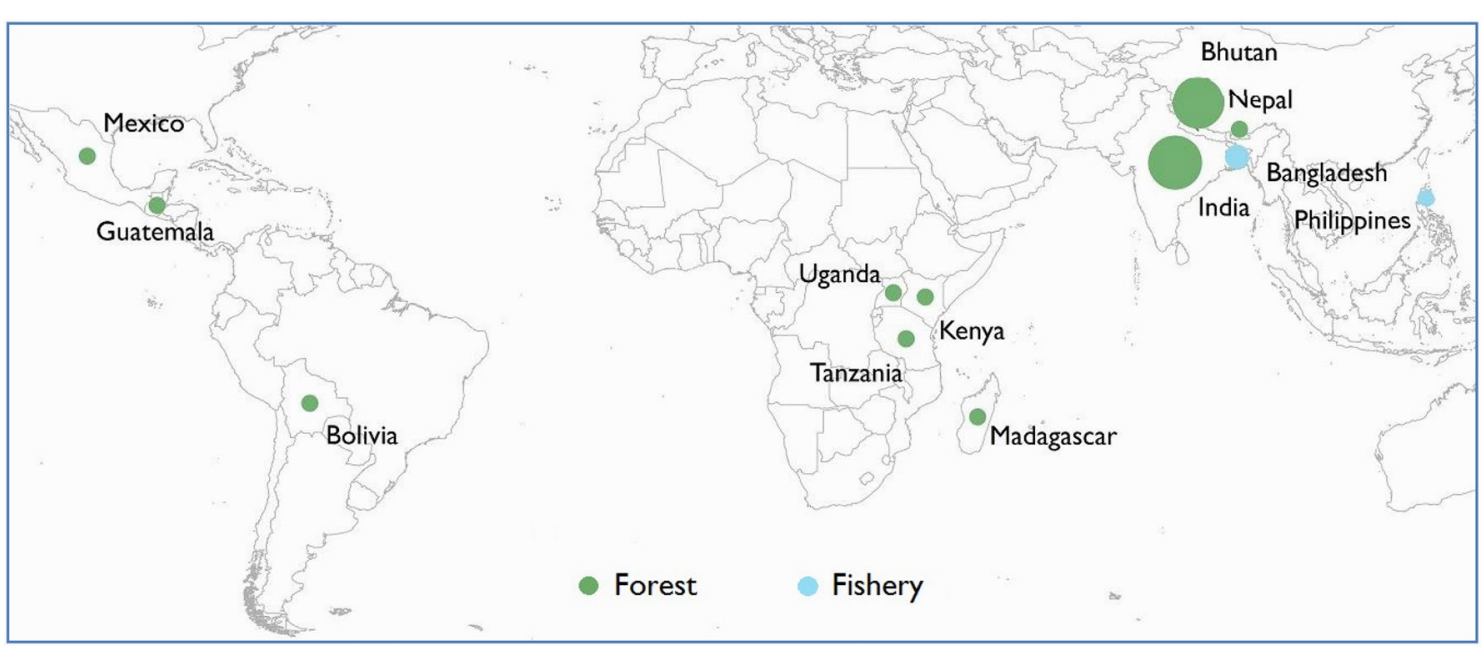

Fig. 2 Geographic distribution and categories of included studies with circles proportional to the number of included studies from a country (excludes one study [62] because its multiple-country and multi-sector results are presented in aggregate)

and two studies mentions high levels of political and/or economic inequality in a community as a negative influence $[8,56]$. To reduce the influence of these factors, several studies use regressions models that control for the impact of factors other than gender and address the issue of omitted-variable bias $[8,17,18,53,54]$.

\section{Gaps in the available evidence}

Forest management is comparatively well studied with 12 of the 17 included articles covering the topic, but most other common forest and fishery interventions are missing from the assembled literature. There are, for example, no included studies that cover reducing emissions from deforestation and forest degradation (REDD), reforestation, or fisheries co-management, and there is only one looking at fisheries protection [61], and two looking at the regulation of fishing $[51,59]$.

\section{Discussion}

The majority of the studies are in forest management and come from India and Nepal. There are several likely reasons for this concentration. India and Nepal were among the first to introduce community forest management on a systematic basis, India in 1990 and Nepal in 1993 [3]. By 2006, India had 106,482 registered Joint Forest Management groups [63], and guidelines on Joint Forest Management issued in 2000 recommend that the general body of Village Forest Committees consist of 50 \% women members, with at least $33 \%$ women on the executive committee [64]. In 2011, Nepal had 17,685 Forest User Groups [65], with approximately 800 women-only groups [66], and government guidelines for community forestry recommend that women comprise $50 \%$ of a Forest User
Group's executive committee [67]. The two countries have created a 'natural experiment' in the gender composition of forest management groups.

\section{Limitations}

The English-language focus may have caused us to miss relevant studies and thus underestimate the available evidence. Two non-English-language studies with English abstracts suggesting relevance were identified during the search ('Additional file 2: full-text review results'). On bias risk, we found no studies that mentioned negative resource governance or conservation effects from including women in a resources management group. Publication bias in which positive or statistically significant results are more likely to be published could be an issue. Our search strategy aimed to minimise publication bias by including a comprehensive search of both the nonacademic and academic literature, and $35 \%(n=6)$ of the included studies were identified from non-academic sources. This, however, was unlikely to overcome the publication bias towards negative results.

\section{Conclusions}

To answer our primary question, for some areas, such as India and Nepal, the evidence is strong enough to suggest that including women in forest and fishery management groups can result in better resource governance and conservation outcomes. The substantial gaps, however, in the evidence base and social, economic and ecological differences globally, make it problematic to generalise from this evidence to other geographies. Thus, there is a strong case for extending the research to other countries and regions, as per the more robust studies in India 
and Nepal. The strength of the available evidence also supports a hypothesized theory of change linking the participation of women in forestry and fisheries management groups with better nature resource governance and conservation outcomes. Identifying the likely causal pathways for this theory of change should be a research priority.

\section{Policy and programme implications}

The policy and programme implications beyond South Asia are hindered because the evidence from other regions is limited. At the same time, the conceptual framework provided by existing studies provides a clear case for gathering robust evidence from a diversity of regions on the impact from varying gender compositions of resource management groups.

\section{Research implications}

The results of the systematic map suggest several potential research avenues:

- Additional studies on the impact of the gender composition of forest and fishery management groups in different regions of the world, with regions selected systematically to reflect social, economic, and ecological diversity.

- Identifying the pathways through which women's inclusion in natural resource management leads to better resource governance and conservation outcomes.

\section{Ethical issues and consent}

Ethical approval, consent to participate, and consent for publication are not applicable to this research.

\section{Additional files}

Additional file 1. Evolution of the search strings.

Additional file 2. Full-text review results.

Additional file 3. Study coding results.

Additional file 4. Key findings from included studies.

\section{Authors' contributions}

$\mathrm{CL}$ managed the systematic map process. $\mathrm{CL}, \mathrm{GT}, \mathrm{DP}, \mathrm{FB}, \mathrm{LS}$, and MD drafted the manuscript and BA, EM, DRo, DRu, TS, and DW provided inputs on specific topics and comments on the draft. FB and MD developed the search strategy, with input from $C L$ and GT. CL, MD and FB developed the study coding strategy. MD, FB and $C L$ did the title and abstract screening. $C L, F B$ and $M B$ did the full-text screening with input from GT and DP. CL, GT and MD did the study coding. All authors read and approved the final manuscript.

\section{Author details}

${ }^{1}$ The Nature Conservancy (TNC), 4245 N. Fairfax Drive, Arlington, VA 22203, USA. ${ }^{2}$ ICF International (IFCI), 1725 I St NW \#1000, Washington, DC 20006 , USA. ${ }^{3}$ International Institute for Environment and Development (IIED), 80-86
Grays Inn Road, London WC1X 8NH, UK. ${ }^{4}$ Center for International Forestry Research (CIFOR), Jalan CIFOR, Situ Gede, Sindang Barang, Bogor 16115, Indonesia. ${ }^{5} \mathrm{Global}$ Landscapes Initiative, Institute on the Environment, University of Minnesota, Saint Paul, MN 55108, USA. ${ }^{6}$ School of Environment, Education and Development, University of Manchester, Manchester M13 9PL, UK. ${ }^{7}$ Wildlife Conservation Society (WCS), 2300 Southern Blvd, Bronx, New York, NY 10460, USA. ${ }^{8}$ Forestry and Biodiversity Office, United States Agency for International Development (USAID), 1300 Pennsylvania Avenue Northwest, Washington, DC 20004, USA.

\section{Acknowledgements}

This research benefited from a gift to TNC by Amy Batchelor and Bradley Feld and the generous support of the American people through USAID under MTO 069018 (Biodiversity Fund) and REQ-EGAT-12-000014 (Measuring Impact) managed by the USAID Office of Forestry and Biodiversity/Bureau for Economic Growth, Education and the Environment. DfID's KnowFor provided funding for the CIFOR and IIED contributions. IIED also received support from Danida (Denmark), Irish Aid, and Sida (Sweden). The authors'views expressed in this publication do not necessarily reflect the views of the United States Agency for International Development or the United States Government or any other donor mentioned above. None of the funders had any role in the design of the study, collection, analysis, and interpretation of the data, or writing the manuscript.

\section{Competing interests}

One co-author (BA) has articles included in the systematic map but did not have any role in the article screening, study coding, or quality assessment.

Received: 11 October 2015 Accepted: 8 March 2016

Published online: 21 March 2016

\section{References}

1. Otto J, Zerner C, Robinson J, Donovan R, Lavelle M, Villarreal R, Salafsky N, Alcorn J, Seymour F, Kleyneyer C. Natural connections: perspectives in community-based conservation. Washington: Island Press; 2013.

2. Dressler W, Büscher B, Schoon M, Brockington D, Hayes T, Kull CA, McCarthy J, Shrestha K. From hope to crisis and back again? A critical history of the global CBNRM narrative. Environ Conserv. 2010;37:5-15.

3. Agrawal A, Gibson CC. Enchantment and disenchantment: the role of community in natural resource conservation. World Dev. 1999;27:629-49.

4. Tole L. Reforms from the ground up: a review of community-based forest management in tropical developing countries. Environ Manage. 2010;45:1312-31.

5. Pretty J. Social capital and the collective management of resources. Science. 2003;302:1912-4.

6. Wade R. Village Republics. Cambridge: Cambridge University Press; 1989.

7. Ostrom EE, Dietz TE, Dolšak NE, Stern PC, Stonich SE, Weber EU. The drama of the commons. Washington: National Academy Press; 2002

8. Agarwal B. Gender and forest conservation: the impact of women's participation in community forest governance. Ecol Econ. 2009;68:2785-99.

9. Gutiérrez NL, Hilborn R, Defeo O. Leadership, social capital and incentives promote successful fisheries. Nature. 2011;470:386-9.

10. Sunderland T, Achdiawan R, Angelsen A, Babigumira R, Ickowitz A, Paumgarten F, Reyes-García V, Shively G. Challenging perceptions about men, women, and forest product use: a global comparative study. World Dev. 2014;64:S56-66.

11. Kleiber D, Harris LM, Vincent AC. Gender and small-scale fisheries: a case for counting women and beyond. Fish Fish. 2015;16:547-62.

12. Fsdsd AO. The state of world fisheries and aquaculture. Rome: UN Food \& Agriculture Organization; 2012.

13. Agarwal B. Participatory exclusions, community forestry, and gender: an analysis for South Asia and a conceptual framework. World Dev. 2001;29:1623-48.

14. Cornwall A. Whose voices? Whose choices? Reflections on gender and participatory development. World Dev. 2003;31:1325-42.

15. Curtis M, Schmid C, Struber M. Gender diversity and corporate performance. Research Institute Credit Suisse. 2012. 
16. Apesteguia J, Azmat G, Iriberri N. The impact of gender composition on team performance and decision making: evidence from the field. Manage Sci. 2012;58:78-93.

17. Agarwal B. Rule making in community forestry institutions: the difference women make. Ecol Econ. 2009;68:2296-308.

18. Agarwal B. Chapter 5: from exclusion to enpowered engagement. In: Gender and green governance: the political economy of women's presence. Oxford: Oxford University Press; 2010. p. 169-216.

19. Guidelines for systematic review and evidence synthesis in environmental management [http://www.environmentalevidence.org/Documents/ Guidelines/Guidelines4.2.pdf]

20. Gutierrez-Montes I, Emery M, Fernandez-Baca E. Why gender matters to ecological management and poverty reduction. In: Integrating ecology and poverty reduction. Springer: Berlin; 2012. p. 39-59.

21. Cornwall A. Taking off international development's straightjacket of gender. Brown J World Aff. 2014;21:127-39.

22. Agarwal B. "Bargaining" and gender relations: within and beyond the household. Feminist Econ. 1997;3:1-51.

23. FRA 2015 terms and definitions. Forest resources assessment working paper 180. [http://www.fao.org/docrep/017/ap862e/ap862e00.pdf]

24. Borrini-Feyerabend G, Dudley N, Jaeger T, Lassen B, Broome NP, Phillips A. Governance of protected areas: from understanding to action. Best practice protected area guidelines series 20. Switzerland: IUCN; 2013.

25. Issues in poverty reduction and governance [http://www.usaid.gov/sites/ default/files/documents/1862/issues-in-poverty-reduction-and-naturalresource-management.pdf].

26. What is Governance? [http://go.worldbank.org/G2CHLXX0Q0]. Accessed 1 Feb 2016.

27. Leisher C, Temsah G, Booker F, Day M, Agarwal B, Matthews E, Roe D, Russell D, Samberg L, Sunderland T. Does the gender composition of forest and fishery management groups affect resource governance and conservation outcomes: a systematic map protocol. Environ Evid. 2015;4:1-7.

28. [http://www.cabi.org]. Accessed 1 Feb 2016.

29. [http://ovidsp.ovid.com/]. Accessed 1 Feb 2016

30. [http://www.scopus.com/]. Accessed 1 Feb 2016.

31. [http://www.cabi.org/cabthesaurus/]. Accessed 1 Feb 2016.

32. [http://agris.fao.org/agris-search/index.do]. Accessed 1 Feb 2016.

33. [http://agricola.nal.usda.gov/]. Accessed 1 Feb 2016.

34. [http://scholar.google.co.uk/]. Accessed 1 Feb 2016

35. [https://www.google.com/]. Accessed 1 Feb 2016.

36. [http://povertyandconservation.info/]. Accessed 1 Feb 2016.

37. [https://sites.google.com/a/usaid.gov/gender-environment-workinggroup/home?pli=1]. Accessed 1 Feb 2016.

38. Environmental Evidence Journal [http://www.environmentalevidencejournal.org/]. Accessed 1 Feb 2016.

39. International Initiative for Impact Evaluation [http://www.3ieimpact.org/]. Accessed 1 Feb 2016.

40. The Campbell Collaboration [http://www.campbellcollaboration.org/]. Accessed 1 Feb 2016

41. Fleiss JL. The measurement of interrater agreement. Stat Methods Rates Proportions. 1981;2:212-36.

42. Wallace BC, Small K, Brodley CE, Lau J, Trikalinos TA. Deploying an interactive machine learning system in an evidence-based practice center: abstrackr. In Proceedings of the 2nd ACM SIGHIT International Health Informatics Symposium. ACM; 2012. p. 819-24.

43. Rathbone J, Hoffmann T, Glasziou P. Faster title and abstract screening? Evaluating Abstrackr, a semi-automated online screening program for systematic reviewers. Syst Rev. 2015;4:1-7.

44. [http://www.endnote.com].

45. Farrington DP, Gottfredson DC. Sherman LW. Welsh BC: The Maryland scientific methods scale. Evidence-based crime prevention; 2002. p. 13-21.

46. Critical Appraisal Skills Programme, Qualitative Research Checklist 31.05.13 [http://media.wix.com/ugd/dded87_29c5b002d99342f788c6ac 670e49f274.pdf].

47. Buscemi N, Hartling L, Vandermeer B, Tjosvold L, Klassen TP. Single data extraction generated more errors than double data extraction in systematic reviews. J Clin Epidemiol. 2006;59:697-703.

48. [http://office.microsoft.com/en-gb/excel/].
49. Acharya K, Gentle P. Improving the effectiveness of collective action: sharing experiences from community forestry. Thailand: International Research Workshop on Gender and Collective Action; 2006.

50. Buchy M, Rai B. Chapter 7: do women-only approaches to natural resource management help women? The case of community forestry in Nepal. In: Gender and natural resource management: livelihoods, mobility and interventions. London: Earthscan; 2008. p. 127-49.

51. Clabots BM. Gender dimensions of community-based management of marine protected areas in Siquijor, Philippines: Thesis, University of Washington; 2013

52. McDougall C, Jiggins J, Pandit BH, Thapa Magar Rana SK, Leeuwis C. Does adaptive collaborative forest governance affect poverty? Participatory action research in Nepal's community forests. Soc Natural Resour. 2013;26:1235-51.

53. Agarwal B: Chapter 7: violations and penalties. In: Gender and green governance: the political economy of women's presence. Oxford: Oxford University Press; 2010. p. 259-90.

54. Agarwal B. Chapter 9: shortages admidst growing plenty. In: Gender and green governance: the political economy of women's presence. Oxford: Oxford University Press; 2010. p. 323-52.

55. Agrawal A, Yadama G, Bhattacharya A. Decentralization and environmental conservation: gender effects from participation in joint forest management. Thailand: International Research Workshop on Gender and Collective Action; 2006.

56. Coleman EA, Mwangi E. Women's participation in forest management: a cross-country analysis. Glob Environ Change. 2013;23:193-205.

57. Das N. Women's dependence on forest and participation in forestry: a case study of joint forest management programme in West Bengal. J Forest Econ. 2011;17:67-89.

58. Das N. Impact of participatory forestry program on sustainable rural livelihoods: lessons from an Indian province. Appl Economic Perspect Policy 2012;34:428-453.

59. Kabir GS, Yew TS, Noh KM, Hook LS. Assessing fishers' empowerment in inland openwater fisheries in Bangladesh. Ecol Econ. 2011;70:2114-23.

60. Mehra D. Gender equity in forest management: case studies from Vidarbha region of Maharashtra state. Thirteenth biennial conference of the international association for the study of commons (IASC) on 'Sustaining commons: sustaining our future' 2011.

61. Sultana P, Thompson P. Gender and local floodplain management institutions: a case study from Bangladesh. J Int Dev. 2008;20:53-68.

62. Westermann O, Ashby J, Pretty J. Gender and social capital: the importance of gender differences for the maturity and effectiveness of natural resource management groups. World Dev. 2005;33:1783-99.

63. Bhattacharya P, Pradhan L, Yadav G. Joint forest management in India: experiences of two decades. Resour Conserv Recycl. 2010;54:469-80.

64. Murali K, Sharma M, Rao RJ, Murthy IK, Ravindranath N. Status of participatory forest management in India: an analysis. In: Joint forest management and community forestry in India: an ecological and institutional assessment. New Delhi: Oxford \& IBH; 2000. p. 25-58.

65. CFUG Database Record available in MIS [http://dof.gov.np/image/data/ Community Forestry/cfdatabase.pdf].

66. Giri K. Gender in forest tenure. Prerequisite for sustainable forest management in Nepal. The Rights and Resources Initiative (RRI) Brief 1. Washington DC: RRI; 2012. p. 1-24.

67. Pokharel RK, Tiwari KR. Good governance assessment in Nepal's community forestry. J Sustain For. 2013;32:549-64. 